\title{
Cognitivism about Practical Rationality
}

\author{
John Brunero
}

Cognitivism about practical rationality is the view that some rational requirements governing intentions can be explained by the rational requirements governing beliefs. Cognitivists tend to focus on two requirements of practical rationality in particular: a consistency requirement on intentions, and a requirement of means-ends coherence. Cognitivism about these practical requirements might seem promising. After all, we're very comfortable speaking of consistency and coherence requirements governing beliefs. And many have thought that intentions involve beliefs in some way. And so it's natural to think that the rational requirements governing those involved beliefs might explain the rational requirements governing those intentions.

To get a sense of how such an explanation might go, consider how a cognitivist might explain a simplified version of a consistency requirement governing intentions,

Intention Consistency: Rationality requires that [if one intends to $\mathrm{X}$, then one does not intend not to $\mathrm{X}]$. $^{1}$

The cognitivist could first point to a similar consistency requirement governing beliefs:

Belief Consistency: Rationality requires that [if one believes that $\mathrm{P}$, then one does not believe that $\sim \mathrm{P}]$.

And she could then defend a thesis about the way intentions involve beliefs:

Strong Belief Thesis: Intending to X involves believing that one will X.

If the Strong Belief Thesis is true, whenever one intends to $\mathrm{X}$ and intends not to $\mathrm{X}$, one has inconsistent beliefs about what one will do: a belief that one will $\mathrm{X}$ and a belief that one will not $\mathrm{X}$. This suggests that Intention Consistency can be explained by Belief Consistency and the Strong Belief Thesis: it's irrational to have inconsistent intentions because, in doing so, you'll have inconsistent beliefs about what you will do, which is irrational.

This is a simplified version of a consistency requirement on intentions since rationality requires not just that our intentions be consistent with one another, but also that they be consistent with our beliefs. For example, I would be irrational if I intended to travel to New York this afternoon and intended to travel to San Francisco this afternoon, while believing that if I travel to New York this afternoon, I won't travel to San Francisco this afternoon. But the cognitivist employing the Strong Belief Thesis will have no trouble here since the associated beliefs - that I'll travel to New York this afternoon, that I'll travel to San Francisco this afternoon, and that if I travel to New York this afternoon, I won't travel to San Francisco this afternoon - are jointly inconsistent.

1 These requirements are wide-scope requirements in that the scope of "requires" ranges over a conditional. See Broome (1999). 
Cognitivist approaches to practical rationality have both their defenders (including Gilbert Harman, David Velleman, Jay Wallace, and Kieran Setiya) and their critics (most notably, Michael Bratman). ${ }^{2}$ In this paper, I'm going to follow the trend in the literature and focus in particular on the prospects for cognitivism about means-ends coherence (also often referred to as "instrumental rationality"). Means-ends coherence, roughly speaking, requires that we intend the means we think are necessary for achieving our ends. For instance, a requirement of means-ends coherence prohibits me from intending to travel to New York this afternoon, believing I'll travel to New York this afternoon only if I intend to buy an airplane ticket, but not intending to buy an airplane ticket. ${ }^{3}$ Someone who finds herself with this prohibited combination of attitudes could escape in three ways: coming to intend the means of buying the ticket, giving up her end of travelling to New York this afternoon, or revising her instrumental belief. So far as the requirement of means-ends coherence is concerned, there is no specific way one must proceed. For this reason, the requirement is often formulated as a wide-scope requirement, in that "requires" ranges over a conditional:

Means-Ends Coherence: Rationality requires that [if one intends to E, and believes that one will $\mathrm{E}$ only if one intends to $\mathrm{M}$, then one intends to $\mathrm{M}] .{ }^{4}$

This formulation is no doubt in need of further refinement. ${ }^{5}$ But since the details won't matter here - except for a brief point I'll make in $\$ 2.3$ - we can work with this rough formulation.

I'll start ( $(1)$ by considering the prospects for a cognitivist account of Means-Ends Coherence that appeals to the Strong Belief Thesis. I'll argue we should reject such accounts since the Strong Belief Thesis is either false or it's restricted in such a way that it can’t do the explanatory work the cognitivist needs it to do. I then (\$2) consider the prospects for a cognitivist account that doesn't appeal to the Strong Belief Thesis, but instead to some weaker thesis about the connection between intention and belief. I start with Wallace's cognitivist account, present two objections to it, and then present an account that's similar but avoids these objections. I defend the key assumptions of this account, and argue it's the best available cognitivist account of Means-Ends Coherence.

However, the best isn't good enough. I argue (§3) that while cognitivists might be able to show that every instance of means-ends incoherence involves incoherence in belief, they haven't established that the theoretical requirements explain the practical ones. I argue that there are two reasons to doubt cognitivism's explanatory thesis. First, we should expect a theory that explains Means-Ends Coherence to also be able to explain

\footnotetext{
2 See Harman (1976), (1986), Velleman (1989), (2007), Wallace (2006), and Setiya (2007). See Bratman (1987), (2009), (2009b).

3 The instrumental belief refers to an intention thought to be necessary for achieving an end. Note that Means-Ends Coherence should not be understood to apply to every believed necessary condition for achieving an end. For instance, consider expected side effects. Suppose I intend to grade fairly, but believe I'll do so only if I hurt the feelings of some students. Surely I'm not rationally required to intend to hurt their feelings (or revise my other attitudes). But I am rationally required to form those intentions I think necessary for my grading fairly. Suppose I think I'll grade fairly only if I intend to blind the papers. In that case, it does seem that I'm required to intend to blind the papers (or revise my other attitudes).

${ }^{4}$ See Broome (1999).

${ }^{5}$ See Kolodny and Brunero (2013), §3, and Setiya (2007), pp. 667-668.
} 
closely related practical requirements, but cognitivism seems unable to do this. Second, if we consider all the relevant theoretical requirements that apply, and not simply select out some and ignore others, cognitivism issues false predictions about the rationality of ways of escaping from a state of means-ends incoherence.

\section{GOGNITIVISM WITH THE STRONG BELIEF THESIS}

Some philosophers have developed cognitivist explanations of Mean-Ends Coherence using the Strong Belief Thesis. ${ }^{6}$ Let's consider how such an explanation might go. Suppose I'm instrumentally incoherent: I intend to travel to New York this afternoon, believe I'll get there only if I intend to buy an airplane ticket, but don't intend to do this. According to the Strong Belief Thesis, I believe

(1) I will travel to New York this afternoon.

If we pair this belief with my instrumental belief

(2) I will travel to New York this afternoon only if I intend to buy an airplane ticket,

and apply the theoretical rational requirement

Closure: Rationality requires that [if one believes that $\mathrm{P}$, and that if $\mathrm{P}$ then $\mathrm{Q}$ then one believes that Q]

then rationality requires that our instrumentally incoherent agent either give up his belief (1), which, by the Strong Belief Thesis, would involve his not intending to travel to New York this afternoon, and so would involve his escaping instrumental incoherence, or give up his belief (2), which would also constitute an escape from instrumental incoherence, or come to believe

(3) I intend to buy an airplane ticket.

This gets us quite close to a cognitivist explanation of Means-Ends Coherence, but not all the way there, since it seems possible for one to believe one intends to do something without actually intending to do it. But if one can close this gap by showing how it is independently theoretically irrational to have false beliefs about one's intentions in this context, then one would have a cognitivist explanation of Means-Ends Coherence in terms of Closure and the theoretical requirement not to have false beliefs about one's intentions in this context. ${ }^{7}$ However, this cognitivist explanation will only be as plausible as the Strong Belief Thesis. The remainder of this section will be devoted to the question of whether that thesis is true.

\footnotetext{
${ }^{6}$ See Setiya (2007), pp. 663-671. Setiya's account differs slightly from sketch given below in ways that won't matter for the following discussion.

${ }^{7}$ For an attempt to close this gap, see Setiya (2007), pp.670-671. For arguments that the gap remains open, see Bratman (2009), §4, and Brunero (2009), §1.
} 


\subsection{The Strong Belief Thesis}

According to the Strong Belief Thesis, intending to $\mathrm{X}$ involves believing one will $\mathrm{X}$. But this need not preclude one from also believing one's belief could be false. Just as I could believe that my friend Dana will be in New York this afternoon, but also believe that I could be wrong about this, when I intend to travel to New York this afternoon, and so believe that I will, I could also believe that I could be wrong about this. The Strong Belief Thesis is compatible with one's being a fallibilist about the involved beliefs. ${ }^{8}$

However, one might still worry that the Strong Belief Thesis is vulnerable to counterexamples. Critics of the thesis usually present cases involving an agent intending to do something difficult, where, it is alleged, the agent intends to $\mathrm{X}$, but doesn't believe that she will X. Some examples include a golfer intending to sink a difficult putt, an amateur basketball player intending to make a half-court shot, and someone intending to leap across a wide gap. Defenders of the Strong Belief Thesis aren't persuaded by these alleged counterexamples, and they usually reply by denying that these really are cases in which one intends to sink the putt, make the shot, leap across the gap, and so forth. ${ }^{9}$ Since the Strong Belief Thesis has been discussed for many years now, with some very capable philosophers being convinced by these alleged counterexamples, and other equally capable philosophers not being convinced by them, we might get the impression that the cognitivist wouldn't face significant costs in proceeding on the assumption that the Strong Belief Thesis is true. ${ }^{10}$ I think this impression is mistaken. I'll argue that those argumentative maneuvers needed to save the Strong Belief Thesis from these counterexamples, if successful, undermine the cognitivist's broader explanatory project. I'll argue that the cognitivist employing the Strong Belief Thesis thus faces a dilemma: she must either concede that the Strong Belief Thesis is false or maintain that it's true but unable to play the explanatory role that the cognitivist needs it to play. Either way, cognitivist explanations employing the Strong Belief Thesis fail. If this is right, the prospects for cognitivism with the Strong Belief Thesis are not as good as they might initially appear.

So, let's now turn to some alleged counterexamples. First, let's consider the case of someone who intends to lift a heavy log that has fallen onto his front porch. Plausibly,

\footnotetext{
${ }^{8}$ See Harman (1986), p. 92.

9 One way to proceed would be to consider our linguistic intuitions about agential expressions of an intention (or lack of an intention) in such cases. Suppose the golfer makes the difficult putt. On the one hand, if she were to say, "I intended to make that," she comes across as bragging. (Harman 1986, p. 91) However, this might merely be a feature of Gricean conversational pragmatics; notice that the implicature of overconfidence can be cancelled by, for instance, her saying, "I intended to make that, but really didn't think I would." And there's also some linguistic evidence pointing in the other direction: it would sound odd for the golfer to say, "I had no intention of making it." (Adams 2007, p. 151-152). In this paper, we can avoid putting much weight on such arguments. Our question is more manageable: can the Strong Belief Thesis be true in a way that lends support to the cognitivist explanation of Means-Ends Coherence? I think we can answer this question in the negative without having to rely on linguistic intuitions of this sort.

${ }^{10}$ For instance, the Strong Belief Thesis is endorsed by Hampshire and Hart (1958), Grice (1971), Harman (1976), (1986), Velleman (1989), (2007), and Davis (1984). But it is opposed by Audi (1973), Davidson (1980), and Mele (1992); Bratman (1987) also expresses skepticism about the thesis, and develops an account of intention that doesn't rely on it. For a very helpful overview of various possible views of the intention-belief connection, see Adams (2007), esp. 143-147. Adams also opposes the Strong Belief Thesis.
} 
he intends to lift the log but doesn't believe that he will. It's not that he believes he won't; he's simply agnostic about whether he will. Second, let's consider Bratman's famous case of an absent-minded cyclist who intends to stop by the bookstore on the way home, but, aware of his tendency to go on "autopilot" once on his bike, doesn't believe that he will. Again, he's agnostic about whether he'll succeed in doing what he intends to do. ${ }^{11}$ (While the first example involves one having doubts about whether one's actions will produce the intended result, the second involves one having doubts about whether one will perform the requisite actions at the appropriate time.)

One way to defend the Strong Belief Thesis against such counterexamples, suggested by Gilbert Harman, is to argue that the alleged counterexamples don't involve intentions to do the act believed to be difficult, but only intentions to try to do the act. ${ }^{12}$ For instance, on Harman's suggestion, the man intends to try to lift the heavy log, and the absent-minded cyclist intends to try to stop by the bookstore. We need to be careful about what's being claimed here. It's plausible to think that when a speaker says, "I intend to try to X," she's expressing the thought that she intends to X, and the "try to" is there to express her doubts about success. But this view, of course, would be of no help to the Strong Belief Thesis, since this view concedes that the Strong Belief Thesis is false. For Harman's suggestion to save the Strong Belief Thesis, it must be the case that in the alleged counterexamples what one intends is to try to $X$-and, moreover, one has this intention to try to $\mathrm{X}$ without also intending to $X$.

Harman's move saves the Strong Belief Thesis, but it's of little help to the cognitivist attempting to explain Means-Ends Coherence. Let's suppose we follow Harman in thinking that the man really only intends to try to lift the log. Intuitively, if this man were to believe that he'll lift the log only if he bends his knees when he lifts, and were to fail to intend to bend his knees when he lifts, he would be criticizable as means-ends incoherent. But he might think that bending one's knees, while necessary for lifting the log, isn't necessary for trying to lift the log. After all, we could suppose that the last time he didn't bend his knees, he tried and failed to lift the log, but didn't fail to try to lift the log. So, if his intention is merely to try to lift the log, he is no longer criticizable as means-ends incoherent in failing to intend to bend his knees. He's no longer failing to intend means believed necessary for achieving his end. But, intuitively, this is the wrong thing to say; surely he is criticizable for being means-ends incoherent here.

The same point could be made about Bratman's cyclist. He may believe that intending, at the relevant time, to turn left on Bookstore Lane is a necessary means to stopping by the bookstore, but not believe it's a necessary means to trying to stop by the bookstore. After all, he may know that the last time he tried to stop by the bookstore, he failed to stop by precisely because he didn't intend, at the relevant time, to turn left on Bookstore Lane. But he didn't fail to try to stop by the bookstore. ${ }^{13}$ Since intending to turn down Bookstore Lane isn't believed by him to be a necessary means to carrying out his intention to try to stop by the bookstore, he isn't means-ends incoherent in failing to

\footnotetext{
11 Bratman (1987), p. 32.

${ }^{12}$ Harman (1986), pp. 90-94.

13 In this case, he doesn't go to the bookstore because of his own forgetfulness, rather than because of any external impediment. But we don't want to say that if the relevant failure is "internal" then one doesn't make an attempt. That would rule out the possibility of one's trying to, say, solve a math problem in one's head, or remember an anniversary.
} 
form that intention. But that's the wrong result, since surely he is means-ends incoherent in failing to form that intention.

The problem here is that there is, intuitively, a requirement of means-ends coherence that applies to the cyclist and the log-lifter. If the Strong Belief Thesis is false, the cognitivist can't account for this requirement in the standard way (as in the sample explanation of Means-Ends Coherence given above). But if we save the Strong Belief Thesis by saying that these cases involve only intentions to try, we still are unable to explain this requirement, since the agent, while believing that forming certain intentions (to bend at the knees; to turn down Bookstore Lane) is necessary for achieving an end, might not believe that forming these intentions is necessary for trying to achieve those ends. And so what should count as a case of criticizable means-ends incoherence isn't so counted by the cognitivist.

Another way to save the Strong Belief Thesis from these counterexamples, originally suggested by Harman but developed by Velleman in Practical Reflection, is to argue that "intend" is ambiguous, and the Strong Belief Thesis holds for only one sense of "intend." Velleman writes:

The words 'intention' and 'intend' are thus ambiguous. They are used to denote, on the one hand, the agent's attitude toward outcomes that are settled, from his perspective, at the close of deliberation and, on the other hand, his attitude toward outcomes whose pursuit is the topic of his deliberation but whose attainment is not thereby settled. In other words, they are used to denote both plan-states and goal-states of the agent. ${ }^{14}$

On this view, the log-lifter would have the goal of, but not plan on, lifting the log, since the outcome isn't "settled from his perspective." But since the Strong Belief Thesis is restricted to the sense of "intend" denoting "plan-states," such examples are not counterexamples to the thesis.

But this is of little help to the cognitivist, since Means-Ends Coherence governs intentions in both senses - that is, in both the "plan-state" and "goal-state" senses of "intend." For instance, the log-lifter would be instrumentally incoherent in intending (in the "goal-state" sense) to lift the log, believing that he'll lift the log only if he intends to bend his knees, and not intending to bend his knees. The cognitivist saves the Strong Belief Thesis, but at the cost of no longer being able to explain why Means-Ends Coherence applies in every case in which it does.

\subsection{Arguments for the Strong Belief Thesis}

So far, I've argued that we should reject the Strong Belief Thesis - or, at least, reject the idea that the thesis can be both true and useful to a cognitivist explanation of Means-Ends Coherence. In the remainder of this section, I'll consider and assess some arguments that have been given for the Strong Belief Thesis. In particular, I'll focus on some recent work by David Velleman, who argues that we need to accept the Strong Belief Thesis if we are to explain certain characteristic functions of intentions, and explain why intentions are

14 Velleman (1989), p. 112. See also Harman (1986), p. 93-94. 
governed by rational requirements like Means-Ends Coherence and Intention Consistency. I'll consider four arguments, and explain why none of them are persuasive.

First, Velleman reminds us of Elizabeth Anscombe's view that the natural expression of an intention to $\mathrm{X}$ is "I am going to X." It seems that if one is sincerely asserting this, then one believes that one will X. As Velleman observes, the assertion, "I am going to X, but I don't believe that I will" appears to be an instance of Moore's paradox. ${ }^{15}$ One might think this is some evidence for the Strong Belief Thesis - namely, that without the Strong Belief Thesis, Moore-paradoxical assertions would be licensed. But I don't think this is right, since Anscombe's remark could be evidence for the Strong Belief Thesis only if it is understood as a universal generalization - that is, as something like, "For all intentions, the natural expression of the intention is 'I am going to X" - and that generalization seems to be shown to be false by the very same examples that challenge the Strong Belief Thesis. For instance, for the person intending to make the difficult putt, "I am going to make it" doesn't seem to be the natural expression of his intention. Something expressing less confidence - like "I am going to try to make it" would better reflect his appreciation of the difficulty involved in making the putt, and hence be the more natural thing to say in this context. And no Moore-paradoxical results emerge if this less confident assertion is paired with one's asserting, "But I don't believe that I will." 16

Let's now turn to a second argument from Velleman - one central to our concerns here - which holds that the Strong Belief Thesis is needed to explain MeansEnds Coherence. Velleman writes:

Why, for example, should an agent be rationally obliged to arrange means of carrying out an intention, if he is agnostic about whether he will in fact carry it out? Suppose that I form an intention to fly to Chicago next Tuesday, well knowing that I often forget to take trips that I have planned. (I am even more forgetful than Bratman.) Buying a ticket for my flight to Chicago will turn out to have been a waste of money if I forget to take the trip. ... But why should I be categorically required to invest in means whose benefits I am not yet prepared to believe in? If I am still entertaining the possibility that a ticket will go to waste, why shouldn't I weigh its expected benefits against those of alternative investments? 17

The idea here seems to be that if we think one could intend to fly to Chicago without believing one will do so, then we have no explanation for why there would be a rational requirement to intend the means of buying a ticket, for doing so should be viewed by the agent as a potential waste of money given his agnosticism about whether he'll go.

Velleman might be right that there would be no categorical requirement for the agnostic traveler to intend to buy the ticket. But it doesn't follow from this that Means-

\footnotetext{
15 Velleman (2007), p. 206-7.

16 As an anonymous referee correctly observed, the defender of the Strong Belief Thesis could deny that one intends to $X$ in such cases, and insist that one only intends to try to $X$ - a strategy we've already rejected as unhelpful to the cognitivist - and then insist that it's still the case that the natural expression of an intention to $X$ is "I am going to $\mathrm{X}$." However, this shows that the argument from Anscombe's remark will be convincing only to those who already accept a controversial response to the alleged counterexamples.

17 Velleman (2007), p. 205.
} 
Ends Coherence doesn't apply to the agnostic traveler. Means-Ends Coherence is a wide-scope requirement; what it requires is that one either intend the means, or abandon the end, or give up one's instrumental belief. It doesn't follow from one's not being required to intend the means that this disjunctive requirement isn't in place.

Why is Means-Ends Coherence formulated this way? One reason is that it often happens that we recognize an end of ours as imprudent, immoral, or otherwise unreasonable. In such cases, it seems perfectly rational for an agent to give up his end. But if we understood Means-Ends Coherence as a narrow-scope requirement - a categorical requirement to intend the means, as Velleman puts it - we would have to concede that one who abandons an end instead of intending the means violates this rational requirement. But that seems to be the wrong result; abandoning the end instead could involve no irrationality whatsoever. And Velleman's example seems to be precisely the kind of case that motivates the wide-scope formulation in this way. In being agnostic about one's success in getting to Chicago, and seeing the significant expense involved in buying the ticket, the agent would be perfectly rational in giving up the end instead of intending the means.

There are two points to make about Velleman's argument. First, even in cases where one isn't agnostic, but instead believes one will carry out what one intends, it could be rational for one to abandon one's end instead. For instance, one could realize that the expense involved in intending the means is so great that even if one achieves one's end, it isn't worth it. In such cases, it would be false to say that there's a categorical requirement to intend the means. So, insisting on the Strong Belief Thesis won't be enough to block this allegedly bad result.

Secondly, and more importantly, this allegedly bad result isn't actually a bad result. There's no cost in our having to say that, in Velleman's example, there's no narrow-scope requirement to intend the means. There would be a cost in saying that there's no applicable requirement of Means-Ends Coherence. But it doesn't follow from there being no narrow-scope requirement to intend the means that no wide-scope requirement of Means-Ends Coherence is in place. ${ }^{18}$

Velleman offers a third argument for the Strong Belief Thesis: if the Strong Belief Thesis were not true, then we would be unable to explain how intentions function so as to coordinate behavior. Velleman writes:

When an intention coordinates behavior, the agent and his associates proceed on the assumption of its being executed - which would be an odd way to proceed if the agent himself were agnostic on the question. If I am agnostic as to whether I will be in Chicago, why should anyone plan or act on the assumption of my being

\footnotetext{
18 Bratman (2009b), §8, also observes Velleman's mistake of understanding Means-Ends Coherence as a narrow-scope requirement to intend the means. In replying to Velleman's argument, Bratman goes on to develop the idea that intentions have a distinctive aim, in much the same way that belief is sometimes thought, by Velleman and others, to have a distinctive aim. In particular, Bratman suggests that "intentions aim at the coordinated control of action that achieves what is intended" and this explains why Means-Ends Coherence is a rational requirement. Exploring this would take us too far afield. And we need not do so to show that Velleman's argument doesn't succeed. Rather, we can simply note that a crucial premise of Velleman's argument - namely, that if there's no requirement to intend the means, then Means-Ends Coherence does not apply - is false and so this argument for the Strong Belief Thesis is unsound.
} 
there. And why should anyone hesitate to plan or act in ways inconsistent with that eventuality. ${ }^{19}$

In short, Velleman argues that since we already believe that intentions play a role in coordinating behavior, and the Strong Belief Thesis is necessary to explain how intentions play that role, we should believe in the Strong Belief Thesis as well.

Velleman's argument identifies two specific coordinating roles for intentions: intentions coordinate the behavior of both the agent herself and the behavior of her associates. However, it's not clear how this latter coordinating role provides support for the Strong Belief Thesis, since what matters for such coordination is what the associates believe, not what the intending agent herself believes, about whether the intention will be successfully executed. But the Strong Belief Thesis is a thesis about what the intending agent herself believes.

But, putting aside this worry for a moment, it's not clear that when an intention coordinates behavior, one's associates always "proceed on the assumption of its being executed," though they may sometimes do. Suppose we are teammates on a basketball team and you intend to make a shot, and, aware of your intention, I position myself for a rebound. I'm clearly not proceeding on the assumption that you'll execute your intention. Had I proceeded on that assumption, I would have hurried back down the court to set up on defense. Or suppose I'm in the stands watching the game, and someone offers me a bet on whether you'll make the shot. I'd be irrational to proceed on the assumption you'll successfully execute your intention. I should instead consider the probability of your doing so and calculate the expected utility of accepting the bet. And much the same goes for the agent herself. When one coordinates behavior with one's own intentions, one need not proceed on the assumption that one's intention will be successfully executed. The shooter might position herself for a rebound. And she might not bet the farm on making the shot.

So, it's a mistake to characterize the coordinating role of intentions merely in terms of how agents (the actor herself or her associates) plan on the assumption that the intention will be successfully executed. Sometimes we do this. But sometimes we don't, and we instead consider the probability that the intention will be successfully executed. So, with this in mind, we should return to our question: is the Strong Belief Thesis needed to explain the coordinating role of intentions?

Now it seems as though some weaker thesis about the intention-belief connection might actually do a better job of explaining the coordinating role. Consider, for instance, Robert Audi's view of intention. Audi doesn't accept the Strong Belief Thesis, but thinks that intending to $\mathrm{X}$ involves believing that $\mathrm{X}$ is more likely than not. ${ }^{20}$ (According to Audi's view, both Shaquille O'Neal and Wilt Chamberlain intended to make free throws - barely - whereas Ben Wallace hoped, but did not intend, to make them - assuming all were aware of their appalling free throw percentages. ${ }^{21}$ ) On this view, sometimes one will

\footnotetext{
19 Velleman (2007), p. 206.

20 Audi (1973).

${ }^{21}$ Wallace shot $42 \%$ from the line for his career, whereas Wilt shot 51\% and Shaq 53\%. Mele (1992) uses the example of a free throw shooter to argue against Audi's view. See especially pp. 131-132; 136-137. If we look at certain commonly accepted functions of intentions - specifically, the functions of initiating and guiding an agent's actions, coordinating behavior, terminating practical reasoning, etc. - then we won't
} 
intend to $\mathrm{X}$ and believe one will $\mathrm{X}$, whereas other times one will intend to $\mathrm{X}$ and merely believe the probability of one's X-ing is greater than (.5).

Audi's view - which I'm not endorsing here - seems to do a better job explaining the coordinating role of intentions than the Strong Belief Thesis does. Since it allows that sometimes one intends to $\mathrm{X}$ and believes one will $\mathrm{X}$, it can account for all those cases in which we plan on the assumption that one will $\mathrm{X}$. But since it also allows that one can intend to $\mathrm{X}$ without believing one will $\mathrm{X}$, it can also account for some cases where one plans in light of the probability that one will X. So, it turns out that Velleman is wrong, and the Strong Belief Thesis isn't needed to explain the coordinating role of intentions. ${ }^{22}$ Once we consider that not all coordination involves proceeding on the assumption of successful execution, this argument for the Strong Belief Thesis fails.

Of course, Velleman might deny that these really are intentions. He might say that in cases where the behavior of oneself or others is coordinated based on some assessment of probabilities, rather than on an assumption of successful execution, we're not dealing with an agent's intentions - maybe only intentions to try, or intentions in the "goal-state" sense of the term. One odd thing about this possible response (and Velleman's argument in general) is that whether something counts as an intention to X shouldn't depend upon whether or not someone else plans on the assumption that I will X. What does their planning have to do with $m y$ beliefs? Additionally, such a reply would employ strategies we've already rejected as unhelpful to the cognitivist. Also, such a reply would appear to rig the argument from the start: it would be using the Strong Belief Thesis to determine what counts as an intention, thereby narrowing what counts as the relevant coordinating phenomena to be explained, and then saying that we should believe in the Strong Belief Thesis because it's necessary to explain the relevant coordinating phenomena. It wouldn't give us an independent reason for believing in the Strong Belief Thesis to begin with.

Velleman offers a fourth argument for the Strong Belief Thesis, arguing that we can't explain a consistency requirement on intentions unless the Strong Belief Thesis is true:

But why should my intentions be subject to a requirement of consistency if I can remain cognitively uncommitted to their truth? If I am agnostic as to whether I'll be in Chicago on Tuesday evening, why should my plans for Tuesday evening have to be consistent with my being there? ${ }^{23}$

Velleman specifically asks why he shouldn't also make dinner plans somewhere local for Tuesday evening, knowing he won't be able to both be in Chicago and keep the dinner reservation.

notice a difference between, say, O'Neal and Wallace shooting a free throw. So, it seems odd to say that one intends and one doesn't.

${ }^{22}$ Holton (2008) makes the related point that an appeal to partial, as opposed to all-out, belief would allow for a response to Velleman's coordination argument for the Strong Belief Thesis. (Audi's view is that intention involves an all-out belief that success is more likely than not, not a partial belief in success.) Holton argues that intentions, coupled with partial beliefs in success, can play a role in coordinating the behavior of self and others (As Holton correctly observes, one's informing others of one's uncertainty of success facilitates that coordination).

${ }^{23}$ Velleman (2007), p. 206. 
The first thing to note is that we should distinguish cases of inconsistency in intentions, which is irrational, from cases of contingency planning, which need not be irrational. If I doubt I'll succeed in going to Chicago, it may be perfectly rational to put in place a backup plan that involves dinner reservations at a local restaurant. ${ }^{24}$ We aren't tempted to describe such cases of contingency planning as involving an intention to eat at the restaurant; rather, we would say that one intends to eat there if one stays in town. And this contingency plan isn't inconsistent with one's planning to be in Chicago instead.

Additionally, even if such contingency planning involved inconsistency, this wouldn't give us grounds for accepting the Strong Belief Thesis, since we engage in contingency planning even when we believe we'll succeed in our intentions. For instance, when I intend to clear the small pond on the easy par 3 and believe I will, I may still carry an extra ball just in case I'm wrong. So, adopting the Strong Belief Thesis won't help one avoid this supposed inconsistency in intentions.

So, let's assume we're not dealing with a case of contingency planning, but rather a case of someone who intends to be in Chicago and intends to eat at a local restaurant, knowing he can't do both. Velleman asks "why should my intentions be subject to a requirement of consistency if I can remain cognitively uncommitted to their truth?" There are two ways to understand this question. On one reading, Velleman is suggesting that if intentions did not involve cognitive commitment, then there would be no consistency requirement governing intentions. But since there is a consistency requirement governing intentions, it follows that intentions do involve cognitive commitment. On a second reading, Velleman is asking what explanation can be given of a consistency requirement on intentions if it's not the cognitivist one.

Start with the first reading. I don't think Velleman is right that there wouldn't be a consistency requirement on intentions if the Strong Belief Thesis were false. Let's assume it's false. Let's assume again that Audi's weaker view of intention is correct, so that intending to $\mathrm{X}$ involves believing $\mathrm{X}$ is more likely than not. It doesn't follow that we're now rationally permitted to have inconsistent intentions. Consider an example. Suppose I know that Farmer Joe grows five fruits (apples, oranges, plums, pears, and peaches) and every day selects at random only four of those fruits to bring to the Farmer's Market. If Audi's view is correct, in order to intend to buy apples at the Farmer's Market, I must believe it's more likely than not I'll buy apples. But that doesn't present a barrier to my intending to buy apples; I can here intend to buy apples and believe it's more likely than not that I will. Likewise, I can intend to buy oranges, since I believe it's more likely than not that I'll buy oranges. The same goes for the other fruits. But now suppose that I tell you, knowing that Joe brings only four fruits to the market, that I intend to buy apples, intend to buy oranges, intend to buy plums, intend to buy pears, and intend to buy peaches. You would rightly accuse me of irrationality in having these five intentions, while believing Joe will bring only four fruits. This example suffices to show that Velleman is wrong: even if the Strong Belief Thesis is false, one could still have intentions that are rationally criticizable for their inconsistency.

On the second reading, Velleman is challenging his opponent to provide some other explanation of the consistency requirement on intentions if it's not going to be the cognitivist one. This is a hard question. We'd have to provide an account of intentions

${ }^{24}$ Of course, one wouldn't want to invite others to dinner without telling them this is just a contingency plan - that would risk rudeness. 
that shows why having intentions whose contents are inconsistent (or inconsistent with the contents of one's beliefs) is irrational - and, of course, do so without appealing to the involvement of beliefs. Moreover, we'd have to explain how intentions differ from other attitudes, such as desires, where having that attitude towards inconsistent contents need not involve irrationality. There is, after all, nothing irrational about both wanting to go for a smoke (because it's pleasant) and wanting not to go for a smoke (because it's healthy), but there is something irrational about both intending to go for a smoke and intending not to go for a smoke. That's a task too complicated to take on here, but it's also one we need not pursue. Our project is to evaluate the cognitivist's explanation of the requirements of practical rationality, not to propose an alternative theory. And, in any case, the lack of an alternative theory of the consistency requirement on intentions wouldn't constitute a convincing reason for accepting the Strong Belief Thesis.

In summary, although the Strong Belief Thesis might be a philosophically respectable but controversial thesis, I think we should be much less confident that it could both be true and successfully employed in a cognitivist explanation, since those maneuvers needed to save it from counterexamples (saying one merely intends to try, or that "intend" is ambiguous) make it unsuitable to play the necessary role in the cognitivist explanation. And the various arguments I've considered in favor of the thesis aren't convincing as they stand.

\section{GOGNITIVISM WITHOUT THE STRONG BELIEF THESIS}

Perhaps the Cognitivist could account for Means-Ends Coherence without relying on the Strong Belief Thesis. I'll start by introducing an account that's similar to one proposed by Jay Wallace, but able to avoid some difficulties facing Wallace's account, and then I'll defend the key assumptions of that account. I'll argue that this is the best available cognitivist account of Means-Ends Coherence.

\subsection{Towards a Cognitivist Account without Strong Belief}

Wallace's account relies on a weaker thesis about the connection between intention and belief: intending to $\mathrm{X}$ involves believing $\mathrm{X}$ is possible. On this thesis, the person who intends to travel to New York will believe

(4) It is possible for me to travel to New York.

Wallace assumes that his instrumental belief takes the following form:

(5) It is possible for me to travel to New York only if I intend to buy an airplane ticket.

Now suppose that the means-ends incoherent agent, who doesn't intend to buy the ticket, is "minimally self-aware" and so believes

(6) It is not the case that I intend to buy an airplane ticket. 
In that case, the means-ends incoherent agent, Wallace argues, would have inconsistent beliefs. He argues that if you are means-ends incoherent, you will be

left in effect with the following incoherent set of beliefs (assuming you are minimally self-aware): the belief that it is possible that you do $x$, the belief that it is possible that you do $x$ only if you also intend to do $y$, and the belief that you do not intend to do $y$. The incoherence of these beliefs is a straightforward function of the logical relationship among their contents, suggesting that the normative force of the instrumental principle can be traced to independent rational constraints on your beliefs - in particular, to constraints on certain combinations of beliefs... ${ }^{25}$

This cognitivist explanation of Means-Ends Coherence doesn't require the Strong Belief Thesis.

However, one might have worries about this weaker thesis as well. Couldn't one intend to $\mathrm{X}$ while being agnostic about whether one can X? Suppose I intend to go shopping this evening, but I'm not sure whether the only shopping mall in town is open, and so I'm agnostic about whether I can go shopping. It's not that I believe I can't go shopping; I just don't believe I can. ${ }^{26}$ It might be poor planning on my part to form that intention before finding out whether the mall is indeed open, but it seems possible to do so.

Additionally, one might have some doubts about the logical form of the instrumental belief in (5), which may not be obvious. Perhaps what one believes is that the combination of travelling to New York and not intending to buy a ticket is not possible, so that the logical form would be:

$\sim \diamond(\mathrm{N} \& \sim \mathrm{T})$

where "N" is "I travel to New York" and "T" is "I intend to buy a ticket." On Wallace's view, the inconsistency of the beliefs is "a straightforward function of the logical relationship among their contents" which he takes to be:

$$
\begin{aligned}
& \left(4^{\prime}\right) \diamond \mathrm{N} \\
& \left(5^{\prime}\right) \diamond \mathrm{N} \rightarrow \mathrm{T} \\
& \left(6^{\prime}\right) \sim \mathrm{T}
\end{aligned}
$$

But if the logical relationship among their contents were instead

$$
\begin{aligned}
& \left(4^{\prime}\right) \diamond \mathrm{N} \\
& \left(5^{\prime \prime}\right) \sim \diamond(\mathrm{N} \& \sim \mathrm{T}) \\
& \left(6^{\prime}\right) \sim \mathrm{T}
\end{aligned}
$$

\footnotetext{
25 Wallace (2006), p. 106.

26 An anonymous referee has suggested, plausibly, that to intend to go shopping, one must have at least some evidence that one can go shopping. But that still falls short of saying one must believe one can go shopping.
} 
then the contents of the involved beliefs wouldn't be inconsistent. (To see that there's no inconsistency here, consider another example: one might consistently believe Hank isn't going to Nashville, isn't going to Tennessee, can go to Nashville, can go to Tennessee, but can't go to Nashville and not go to Tennessee. $)^{27}$

Here's a reason for thinking Wallace has misidentified the logical form of the instrumental belief. Suppose he is right that the logical form of the instrumental belief is $\diamond \mathrm{N} \rightarrow \mathrm{T}$, the contrapositive of which is $\sim \mathrm{T} \rightarrow \sim \diamond \mathrm{N}$. Possibility and necessity are defined in terms of one another, such that $\sim \diamond \mathrm{N} \rightarrow \square \sim \mathrm{N}$, and so it follows from these two claims that $\sim \mathrm{T} \rightarrow \square \sim \mathrm{N}$. But this seems wrong. This reading licenses us to detach the claim that $\square \sim \mathrm{N}$ via modus ponens from $\sim \mathrm{T}$. But my not travelling to New York this afternoon is surely believed to be a contingent matter, not a necessary one. What I should conclude is that I'm not travelling to New York this afternoon, not that it's necessary that I'm not travelling to New York this afternoon. I don't take my not travelling to New York this afternoon to be necessary; rather, I only take it to be necessary that it's not the case that I both travel to New York this afternoon and not buy a ticket. So, it seems better to understand the logical form of one's instrumental belief as $\square(\sim \mathrm{T} \rightarrow \sim \mathrm{N})$, instead of $\sim \mathrm{T} \rightarrow \square \sim \mathrm{N} .{ }^{28}$

Perhaps there's a way to defend some specific conception of possibility that allows us to avoid these two objections to Wallace's account. ${ }^{29}$ But it might be easier to develop a version of cognitivism that preserves the central insights of Wallace's approach, but avoids the difficulties that come with talk of possibility. I'll here outline such an account, and then defend its components against some objections. ${ }^{30}$ First, let's follow Wallace in assuming that the instrumentally incoherent agent who is minimally self-aware will believe

27 Note that it won't help Wallace to claim intending to travel to New York this afternoon involves believing (4") $\diamond(\mathrm{N} \& \sim \mathrm{T})$. That would indeed generate an inconsistency in belief with $(5 "), \sim \diamond(\mathrm{N} \& \sim \mathrm{T})$, but that would make one's belief $\left(6^{\prime}\right)$ irrelevant to the inconsistency in belief. One's not intending the means, and so believing one doesn't intend the means, wouldn't matter - you've got an inconsistency regardless. But, if we're trying to explain Means-Ends Coherence, whether one intends the means should matter.

28 See Hughes and Cresswell (1996), pp. 14-16.

${ }^{29}$ Perhaps we should understand the possibility involved here as epistemic possibility, so that our subject believes, for instance, in (4), that for all he knows, it's possible that he travels to New York. (Thanks to Mike Titelbaum for this suggestion.) Since it seems mere belief, not knowledge, is relevant to the alleged inconsistency in (4)-(6), the relevant sense of possibility would be doxastic possibility, which Chalmers 2011 helpfully defines as follows: "A scenario [a "maximally specific way the world might be"] is doxastically possible for a subject if and only if it is not doxastically ruled out by any of the subject's beliefs" (62-3). This might circumvent our two objections. First, it's plausible that our agent believes that going shopping isn't doxastically ruled out by any of his beliefs. Second, the detachment of $\square \sim N$ isn't as worrisome, since this should be understood as stating that $\mathrm{N}$ is ruled out by some of the subject's beliefs. However, one might worry that once we establish this as the relevant sense of 'possibility' at work, we should worry about Wallace's intention-belief thesis. Is it true that one can intend to $\mathrm{X}$ only if one believes $\mathrm{X}$ is doxastically possible? Perhaps not. Indeed, cases when one is aware of one's own instrumental irrationality - specifically, when one is aware that one doesn't, but must, intend the means, if one is to $\mathrm{X}$ - might be cases where a subject doesn't believe X-ing isn't ruled out by any of his beliefs. Wallace's thesis now appears false. Moreover, if Wallace's thesis were true, we'd have to say that the subject doesn't really intend to X, and so there is no instrumental irrationality for him to be aware of. That's implausible. (But for further discussion of the notion of possibility at work in Wallace's account, see Wallace (2006), pp. 114-117.)

30 This account is a slight variation on the account that's presented in $\$ 3.4 .3$ of Kolodny and Brunero (2013). 


\section{(7) I do not intend to M.}

Second, let's assume that the agent's instrumental belief takes the following form:

(8) If I do not intend to M, I certainly will not E.

If we apply Closure, then rationality requires that he believe

(9) I certainly will not E,

or revise his other beliefs. Third, let's assume a thesis about the connection between intention and belief that's far weaker than any we've discussed so far:

Very Weak Belief Thesis: Intending to $\mathrm{X}$ involves not believing that one certainly will not $\mathrm{X}$.

According to this thesis, some who believes (9) does not intend to E.

On this account, whenever one is means-ends incoherent, one has beliefs that violate Closure. Moreover, if a means-ends incoherent agent were to come to comply with Closure, he would make revisions that would also remove him from his state of means-ends incoherence. We're assuming that the means-ends incoherent agent believes both (7) and (8). So, he should, according to Closure, either come to believe (9), which, by the Very Weak Belief Thesis, will involve his not intending to $\mathrm{E}$ (thereby removing him from a state of means-ends incoherence), or give up his instrumental belief (8) (thereby removing him from a state of means-ends incoherence) or give up his belief (7), which, we'll assume for now, will involve him forming the intention to $\mathbf{M}$ (thereby removing him from a state of means-ends coherence).

This account differs from Wallace's account in at least two ways. First, instead of holding that intention involves having a certain belief, it holds that intention involves not having a certain belief. Second, like the account we considered in $\S 1$, it employs Closure, rather than a consistency requirement on beliefs. I think this account is preferable since it avoids the two objections to Wallace's account. But challenges could still be raised about the Very Weak Belief Thesis. Additionally, both this account and Wallace's account face an obvious objection: what if someone were to falsely believe she intends the means? Such a person, it appears, wouldn't violate any theoretical requirements of rationality, but would be instrumentally incoherent in not intending the means. I'll first provide some defense of the Very Weak Belief Thesis, and then turn to that objection.

\subsection{The Very Weak Belief Thesis Defended}

Rather than hold that an intention to $\mathrm{X}$ involves having some belief (that one will $\mathrm{X}$; that it's more likely than not one will $\mathrm{X}$; that it's possible to $\mathrm{X}$ ), we're holding merely that intending to $\mathrm{X}$ involves not believing one certainly will not $\mathrm{X}$. But even this view has been challenged. Anscombe has argued that "in some cases, one can be as certain as possible that one will do something, and yet intend not to do it."31 She provides three

31 Anscombe (1957), p. 94 
examples. First, consider someone hanging on a ledge who intends to hold on, but "is as certain as possible that he must let go and fall." Second, consider a prisoner who intends not to break down under torture but is "as certain as possible that he will break down." Third, consider St. Peter, who has it on highly reliable authority that he'll deny he knows Christ three times, but intends not to do so.

There's a common feature to Anscombe's examples: the agent knows that he can carry out his intention for some period of time, but is certain that after some point, he'll no longer be able to do so (though he may not have any precise view about when that point is). For instance, the man on the ledge believes he can hold on for some time, but is certain his fingers will eventually give out. And the prisoner thinks he'll initially resist the demands of his torturers, but is certain his willpower will eventually fade. The relevant question here concerns how we should construe the intentions involved. If we say, for instance, that the person on the ledge intends to hold on for some time, or intends to hold on as long as he can, then we wouldn't have a counterexample to the Very Weak Belief Thesis; he wouldn't be intending to do something he believes he certainly won't do. For it to be a counterexample, he would have to intend to hang on as long as he can and then some, or perhaps intend to hang on for some specific period of time for which he is certain he won't hang on. But once we specify what the relevant contents of his intention must be, if it's to be a genuine counterexample to the Very Weak Belief Thesis, it becomes easier to deny that these really are his intentions. ${ }^{32}$ So, I don't think any of Anscombe's examples provide a conclusive counterexample to the Very Weak Belief Thesis.

Anscombe does give an argument immediately preceding her introduction of the examples. In this passage, she is explaining the plausibility of someone saying, "I am going to $[\mathrm{X}]$ unless I don't" when one intends to X but has doubts about whether one will $\mathrm{X}$. She writes:

'I am going to ... unless I do not' is not like 'This is the case, unless it isn't'. It has an analogue in estimates of the future: 'This is going to happen ... unless it doesn't'. (Someone may prevent it.) This could be said even of an eclipse of the sun; because the verification of predictions awaits the event - and the sun might blow up before the eclipse. It is for this reason that one can be as certain as possible that one will do something, and yet intend not to do it. (93-94)

Anscombe is correct that we can't verify that some predicted event occurs until after that event occurs. But it's unclear how it follows from this that one can be as certain as possible one will X and yet intend not to X. Moreover, if this is Anscombe's motivation for rejecting the Very Weak Belief Thesis, it's unclear why she would limit herself to examples that share the common feature mentioned above (where one believes one will succeed for some time but is certain one will eventually fail), since this line of reasoning would support one's intending any future event that one is as certain as possible one will not do, since, for any future event, one's failure is not yet verified. For instance, I could intend to jump to the moon, or intend to stop the solar eclipse. By Anscombe's reasoning in this passage, we would have to concede such intentions are possible.

So, Anscombe's arguments against the Very Weak Belief Thesis aren't conclusive. Is there anything that could be said in favor of this thesis? I'll here give two reasons to

${ }^{32}$ I here disagree with Holton (2008), who is convinced by these examples. 
think it's true, both of which are grounded in a plausible account of the functions of intentions.

First, one function of intentions is the settling of deliberation. In deliberating about what to do in some future situation, one can now form an intention about what to do then, and carry the results of that deliberation forward until the time of action. ${ }^{33}$ There are obvious advantages to being able to do this. It would take a lot of time and resources to continually deliberate up until the time of action. By forming an intention, we settle on some course of action, and remove the need to continually deliberate, thereby saving deliberative resources. (Of course, sometimes we reopen questions that are settled, especially if we receive new information.) But it's unclear how one could settle deliberation in this way when the course of action one settles upon isn't recognized as a live option. It seems that if my deliberation has settled on my X-ing, but I am certain I will not $\mathrm{X}$, there will be strong pressure to reconsider and instead decide upon a live option.

Second, intentions also function to give direction to further planning. ${ }^{34}$ An agent with an intention will be disposed to form sub-plans for achieving her end. For instance, when I intend to write a paper, I'll be disposed to form further plans at the appropriate times to facilitate my writing it (setting aside time, gathering relevant books from the library, etc.). And my formation of these sub-plans will be guided by my beliefs about how effective various means will be in realizing that end. For instance, if I think a library book by Parfit will help me write my paper, but another book by Williams would be of no use, I'll plan on checking out the Parfit book, and not the Williams book. But if I'm certain that I won't do what I intend to do, it's hard to see how one would be disposed to engage in further sub-planning. Since I'm certain I won't achieve my ends, any further sub-planning toward that end should be seen as ineffective at achieving my end, and so should be treated in the same way I treat the idea of getting the book by Williams that I won't need for my paper. In other words, since, by my lights, no sub-plan will effectively facilitate the achievement of my end, I would not be disposed to engage in any subplanning.

\subsection{Unknown Failures to Intend}

Both of the accounts discussed in $\$ 2.1$ face an obvious objection. What if one didn't intend the means, but didn't believe this? For instance, suppose I never notice that I don't intend to buy a ticket to New York. Or suppose I falsely believe instead that I $d o$ intend to buy a ticket. I violate Means-Ends Coherence, but yet I don't have the relevant belief that would allow for either of these cognitivist explanations of Means-Ends Coherence to get off the ground.

It won't help to deny the possibility of such ignorance and false beliefs. ${ }^{35}$ Nor could we easily claim such a person would be irrational, if we understand rationality as a matter of coherence among one's attitudes, since an agent's being unaware of, or having false beliefs about, the absence of an intention need not involve any incoherence.

\footnotetext{
33 Se Bratman (1987), p.2.

34 See Bratman (1987), p. 3.

35 See Schwitzgebel (2010) for an overview of some of the psychological evidence and philosophical arguments concerning the possibility of mistaken beliefs about our own psychology.
} 
Perhaps the cognitivist's best bet is simply to concede that one isn't instrumentally irrational in such cases. In other words, someone can get off the hook, as far as the charge of instrumental irrationality goes, just by being ignorant of, or having false beliefs about, her not intending the means. This response might not be as far-fetched as it sounds. After all, we can also get off the hook by being ignorant of, or having false beliefs about, the necessary means to our ends. Additionally, precise formulations of the requirement will aim to take into account rational self-trust. ${ }^{36}$ It's not irrational not to intend the means to one's ends when one trusts one will intend the means in the future. For instance, suppose I intend to buy a house next year, and believe that to do so, I must intend to fill out some legal paperwork. I don't currently intend to fill out that paperwork, but I trust that I will when the time comes. It doesn't seem right to accuse me of irrationality. To get off the hook, as far as the charge of instrumental irrationality goes, I can form some (perhaps false) beliefs about my future intentions. But, if we allow that false beliefs about one's future intentions get one off the hook, why not also allow that false beliefs about one's current intentions can get one off the hook as well?

Perhaps this response to the objection isn't convincing. If it isn't, I don't think it poses any threat to the thesis being defended here: that this cognitivist account of MeansEnds Coherence is better than any other available cognitivist account, especially accounts that employ the Strong Belief Thesis, since those accounts will also face a version of this same objection. Recall the account from $\S 1$. Couldn't I come to believe (3) - that I intend to $\mathrm{M}$ - without intending to $\mathrm{M}$ ? This objection is just as much an objection to the account of Means-Ends Coherence based off the Strong Belief Thesis. And so it doesn't challenge my contention that the account sketched in $\$ 2.1$ is the best available cognitivist account of Means-Ends Coherence.

\section{PROBLEMS FOR COGNITIVISM'S EXPLANATORY CLAIM}

But I don't think the best available cognitivist account is good enough. It might be true that whenever one is means-ends incoherent, one also has beliefs that violate requirements of theoretical rationality. But cognitivism makes a further claim: those theoretical requirements explain the practical ones. However, one might doubt this explanatory claim. One might think that even though every violation of Means-Ends Coherence involves a violation of requirements of theoretical rationality, the latter requirements don't explain the former. I'll give two reasons for doubting the explanatory claim.

First, note that cognitivism seems to be unpromising for explaining practical rationality in general. For instance, cognitivism doesn't seem to be a plausible strategy for accounting for the consistency requirement on intentions once we reject the Strong Belief Thesis. Weaker views about the intention-belief connection seem unable to do the trick. For instance, as Bratman observes, if we work with Wallace's view that intending to $\mathrm{X}$ involves believing it is possible to X, we can't explain what's wrong with intending to X and intending not to $\mathrm{X}$ since the associated beliefs (it is possible to $\mathrm{X}$; it is possible not to $\mathrm{X})$ are perfectly consistent with one another. ${ }^{37}$ If we took Audi's view of intentions, the associated beliefs would be inconsistent (X-ing is more likely than not $\mathrm{X}$-ing; not $\mathrm{X}$-ing is

36 See, for instance, Setiya (2007), p. 668.

37 See Bratman (2009b), §3 and Ross (2009), p.245. 
more likely than X-ing) but such a view doesn't help once we expand our stock of intentions. It's irrational to intend to $\mathrm{A}$, intend to $\mathrm{B}$, and intend to $\mathrm{C}$, while believing that if one As and Bs, one will not $\mathrm{C}$. But the associated beliefs (A-ing is more likely than not A-ing; B-ing is more likely than not B-ing; C-ing is more likely than not C-ing) need not be inconsistent. (If the odds of A-ing and the odds of B-ing are each only slightly better than a coin toss, then it wouldn't be more likely than not that one both As and Bs, and so it could still be that $\mathrm{C}$-ing is more likely than not $\mathrm{C}$-ing.)

But besides consistency constraints on intentions and beliefs, there is much more that rationality requires of us. For instance, rationality also prohibits one from believing one ought to $\phi$ but not intending to $\phi$. But no one has given a cognitivist explanation of this Enkratic requirement. Additionally, Means-Ends Coherence is narrowly restricted to our beliefs about necessary means to our ends. But we might think that practical rationality extends beyond this, and has something to say about beliefs about non-necessary means, or about our preferences or values.

It seems that cognitivism can only explain a small part of the relevant phenomena in need of explanation. One might wonder what explanation can be given of these other requirements of practical rationality, and whether that same explanation could then be given for Means-Ends Coherence. If we can find another theory that can explain MeansEnds Coherence and other requirements of practical rationality, we would have reason to prefer that theory to cognitivism. Considering other views would take us too far afield, but we should at least register a suspicion about a theory that can explain only a small part of the relevant phenomena needing to be explained.

But there is a second, more serious, worry about the cognitivist's explanatory claim. The worry is that the cognitivist's explanation appears to work only because she considers some applicable theoretical requirements while ignoring others. Once we consider all the applicable theoretical requirements, it no longer appears plausible to think that Means-Ends Coherence is explained by the requirements of theoretical rationality. Consider someone who violates Closure by believing $\mathrm{P}, \mathrm{P} \rightarrow \mathrm{Q}$ but not believing $\mathrm{Q}$. When one notices one holds this irrational combination of attitudes, one should look to one's reasons for belief in order to determine the appropriate direction of response. Let's assume that $\mathrm{P} \rightarrow \mathrm{Q}$ is a fixed background belief. If one thinks there are really strong reasons for believing $\mathrm{P}$, and relatively weak reasons for not believing $\mathrm{Q}$, then one should escape this irrational state by coming to believe $Q$. However, if one thinks there are strong reasons not to believe $\mathrm{Q}$ and relatively weak reasons for believing $\mathrm{P}$, one should revise one's beliefs in the modus tollens direction instead, and cease to believe P. In short, one's assessment of the relevant reasons for belief determines the appropriate direction of revision. ${ }^{38}$

But now consider our means-ends incoherent agent who, on our cognitivist account, believes he doesn't intend to buy an airplane ticket, and believes he certainly will not travel to New York if he doesn't intend to but an airplane ticket, but does not believe that he certainly will not travel to New York. Let's suppose that he considers the relevant

38 I'll here avoid the complicated task of specifying the principles of rationality governing such revision. But I do think such principles are principles of rationality, not principles of reason. One's assessment of the reasons could be mistaken. For instance, it could be that person who thinks there are strong reasons to believe $\mathrm{P}$ is mistaken, and there are really strong reasons to believe $\sim \mathrm{Q}$ instead. Here, rationality requires him to revise his attitudes in such a way that he comes to have a belief not well-supported by reasons. (A similar point could be made for the practical case.) 
reasons for belief. Presumably, the evidence that he doesn't intend to buy an airplane ticket will be rather strong. Introspection isn't foolproof, but it will normally provide very strong evidence that he doesn't intend to buy an airplane ticket - and there doesn't seem to be any evidence on the other side. Taking into account the requirements of theoretical rationality governing the direction of revision, it seems that in all but the most unusual cases, revision should proceed in only one direction: coming to believe he certainly will not travel to New York (thereby ceasing to intend to travel to New York). Cognitivism thus predicts an asymmetry in the direction of response. ${ }^{39}$

But, as Means-Ends Coherence is usually understood, there is no such asymmetry. (Indeed, if there's any temptation toward thinking there's an asymmetry, it would be toward proceeding in the other direction: coming to intend the means.) Rather, one could escape a state of means-ends incoherence by either abandoning the end, or by coming to intend the means. This symmetrical feature of Means-Ends Coherence is unexplained by the cognitivist account, and so the cognitivist account is inadequate.

In summary, when we consider the requirements of theoretical rationality in an appropriately holistic way - that is, we don't select one requirement and ignore how it interacts with other relevant rational requirements - then we see that the requirements of theoretical rationality offer a poor explanation of Means-Ends Coherence. Theoretical rationality requires that we respond to states of incoherence by revising in light of our assessment of the relevant reasons for belief, which are provided by the evidence, while practical rationality requires that we respond to states of incoherence by revising in light of our assessment of the relevant reasons for action. These rational requirements may not push in the same direction. Specifically, as I've argued, the theoretical requirements issue the false prediction that we should almost always respond to instrumental incoherence by giving up on our ends. So, the cognitivist, while perhaps establishing that violations of Means-Ends Coherence involve violations of theoretical rationality, hasn't established that the requirements of theoretical rationality explain Means-Ends Coherence.

\section{CONGLUSION}

In this paper, I've considered the merits of some possible ways of developing a cognitivist account of Means-Ends Coherence. I've argued that we should reject accounts that rely on the Strong Belief Thesis, since that thesis is either false or unable to do the explanatory work the cognitivist needs it to do, and the arguments for that thesis aren't convincing. I've argued that the cognitivist would do better to work with an account modeled on Wallace's account, but which employs a weaker belief thesis, avoids talk of possibility and necessity, and employs Closure instead of a consistency requirement. However, in the end, I've argued that there is much about practical rationality that cognitivism can't

\footnotetext{
39 Consideration of such asymmetries have played an important role in arguments against the wide-scope formulation of some rational requirements, including, most notably, the Enkratic Requirement. See especially Schroeder (2004) and Kolodny (2005). It is argued that such asymmetries put pressure on us to construe the Enkratic requirement as a narrow-scope requirement to intend to do what we believe we ought to do. If cognitivism is true, we should expect to feel the same pressure toward construing Means-Ends Coherence as a narrow-scope requirement (to abandon the end). That we don't feel such pressure is a reason to think cognitivism is false.
} 
explain, and the explanation it gives of Means-Ends Coherence appears to work only because it considers some theoretical requirements in abstraction from others. ${ }^{40}$

${ }^{40}$ Work on this paper developed out of research for the SEP entry on instrumental rationality, co-authored with Niko Kolodny, and no doubt benefitted much from Niko's contributions to that project. Thanks also to Waldemar Rohloff, Dana Tulodziecki, Eric Wiland, and two anonymous referees for helpful comments on this paper. And thanks to audiences at the University of Missouri, and, especially, the 2012 Wisconsin Metaethics Workshop. 


\section{REFERENCES}

Adams, F., 2007, "Trying with the Hope” in M. Timmons, J. Greco, A. Mele (eds.), Rationality and the Good, Oxford: Oxford University Press.

Anscombe, E., 1957, Intention, Oxford: Basil Blackwell.

Audi, R., 1973, "Intending," Fournal of Philosophy 70(13): 387-403.

Bratman, M., 1987, Intentions, Plans, and Practical Reason, Cambridge, MA: Harvard University Press.

Bratman, M., 2009, "Intention, Belief, and Instrumental Rationality," in D. Sobel and S. Wall (eds.), Reasons for Action, Cambridge: Cambridge University Press, 13-36.

Bratman, M., 2009b, "Intention, Belief, Practical, Theoretical," in S. Robertson (ed.), Spheres of Reason, Oxford: Oxford University Press, 29-62.

Broome, J., 1999, "Normative Requirements," Ratio 12(3): 398-419.

Brunero, J., 2009, "Against Cognitivism about Practical Rationality," Philosophical Studies, 146(3): 311-325.

Chalmers, D. J., 201 1, "The Nature of Epistemic Space," in A. Egan and B. Weatherson, eds. Epistemic Modality, Oxford: Oxford University Press.

Davidson, D., 2001, "Intending," in Essays on Actions and Events, Oxford: Clarendon Press, $2^{\text {nd }}$ edition.

Davis, W., 1984, "A Causal Theory of Intending," American Philosophical Quarterly 21(1): 43-54.

Grice, P., 1971, "Intention and Uncertainty," Proceedings of the British Academy, 57: 263279.

Hampshire, S., \& H. L. A. Hart, 1958, "Decision, Intention, and Uncertainty," Mind, 67: $1-12$.

Harman, G., 1976, "Practical Reasoning," Review of Metaphysics, 29(3): 431-463.

Harman, G., 1986, Change in View: Principles of Reasoning, Cambridge: MIT Press.

Holton, R., 2008, "Partial Belief, Partial Intention," Mind, 117(1): 27-58.

Hughes, G.E. and M. J. Cresswell, 1996, A New Introduction to Modal Logic, London:

Routledge.

Kolodny, N., 2005, "Why be Rational?" Mind 114(455): 507-563.

Kolodny, N. and J. Brunero, 2013, "Instrumental Rationality," in Edward N. Zalta (ed.), The Stanford Encyclopedia of Philosophy (Spring 2013 Edition).

Mele, A. 1992, "Intention, Belief, and Intentional Action," in Springs of Action, Oxford: Oxford University Press.

Ross, J., 2009, "How to be a Cognitivist about Practical Reason," in R. Shafer-Landau (ed.) Oxford Studies in Metaethics, Vol. 4, 243-282.

Schroeder, M., 2004, “The Scope of Instrumental Reason,” Philosophical Perspectives, 18: 337-364.

Schwitzgebel, E., 2010, "Introspection," in Edward N. Zalta (ed.), The Stanford Encyclopedia of Philosophy (Fall 2010 Edition).

Setiya, K., 2007, "Cognitivism about Instrumental Reason,” Ethics, 117(4): 649-673.

Velleman, J. D., 1989, Practical Reflection, Princeton: Princeton University Press.

Velleman, J. D., 2007, "What Good is a Will?," in A. Leist \& H. Baumann (eds.), Action in Context, Berlin: de Gruyter, 193-215. 
Wallace, R. J., 2006, Normativity and the Will, Oxford: Clarendon Press. 